\title{
Carta de Gabriel Marcel sobre Jacques Maritain
}

\section{Presentación}

La carta de Gabriel Marcel sobre Jacques Maritain, que se publica en este número de Diánoia, estuvo guardada en un cajón durante más de 35 años, por respeto a la voluntad del filósofo existencialista. Sin embargo, hoy en día, a más de treinta años de la muerte de los dos filósofos, por el interés del tema y porque es un documento valioso, me parece que ha llegado el momento de publicarla. A continuación haré un breve relato de la forma en que la carta llegó a mis manos.

Conocí a Gabriel Marcel en París en 1967, un año antes de que las revueltas estudiantiles conmocionaran tanto a la capital francesa como a la ciudad de México. No he podido establecer mi relación de parentesco con él - ya que me dice "sobrina"-; sólo recuerdo que la hermana de Jacqueline Boegner, esposa de Marcel ya fallecida, tenía una relación estrecha con mi tía Odille Engelbach, en cuya casa me hospedaba. Lo único que he podido descubrir, rastreando los archivos familiares y con la ayuda de la tecnología, es que tanto la familia Dieterlen como la familia Boegner han representado una tradición ilustrada que ha defendido un protestantismo social y un patriotismo francés a toda prueba. Asimismo, aprendí que miembros de las dos familias tuvieron, a finales del siglo XIX y principios del XX, una amplia participación política en el gobierno de los Vosgos.

Odille, al saber que yo estudiaba filosofía, me consiguió una cita con Marcel. Por supuesto, antes de ir a su casa pasé a la Librairie Philosophique J. Vrin, ubicada en la plaza de la Sorbona, para comprar Essai de philosophie concrète con el objeto de que me lo dedicara. Lo hizo con una letra tan ininteligible que nunca he podido descifrar su contenido.

Marcel, que en aquella época tenía 78 años, vivía en un departamento situado en la calle Tournon, a espaldas del Palacio del Luxemburgo, en el $6^{\circ}$ arrondissement. Al entrar quedé impresionada por las pilas de libros que ocupaban toda la superficie de su departamento. Había libros en la cocina, en el baño y hasta en su cama; ocupaban todo el lugar. Sólo dos sillas estaban vacías y fue en ellas donde nos sentamos a charlar. Hablamos mucho de México; tenía gran interés en saber de nuestro país ya que había sido invitado al Congreso Internacional de Filosofía que se celebró en la ciudad de México, en septiembre de 1963. Por desgracia, 
una enfermedad le impidió venir. Hablamos de Teilhard de Chardin y del impacto que había causado su libro El fenómeno humano. También hablamos de Sartre; aunque difería radicalmente de su pensamiento, le parecía un gran mérito suyo poder "divulgar" su filosofía a través de las obras de teatro. Es importante recordar que Marcel también escribió obras de teatro pero sin lograr la misma influencia que Sartre. No recuerdo haber hablado con él sobre el tomismo; probablemente si lo hubiera hecho no tendría la carta que me envió.

Cuando regresé a México, les narré a mis profesores y colegas de la Universidad Iberoamericana mi conversación con Marcel, suceso que para mí había sido una experiencia memorable.

A finales de 1971 recibí una llamada del padre José Rubén Sanabria, en ese tiempo director de la Revista de Filosofía de la Universidad Iberoamericana, para comentarme que el comité planeaba dedicar los números 14 y 15 de la revista a un homenaje al filósofo tomista Jacques Maritain. Asimismo, me pedía que le escribiera a Marcel pidiéndole unas palabras sobre él. Recuerdo que mi padre me ayudó a redactar la carta en la que solicitaba unas cuantas ideas sobre la persona y la filosofía de Maritain. La contestación no tardó en llegar. Obviamente respeté la voluntad de Marcel y guardé la carta. Hoy en día, agradezco a la revista Diánoia, del Instituto de Investigaciones Filosóficas, el interés mostrado en ella y agradezco a Jorge Alonso su insistencia en que la diera a conocer.

Paulette Dieterlen Instituto de Investigaciones Filosóficas Universidad Nacional Autónoma de México paudie@filosoficas.unam.mx 


\author{
Madenoiselle Paulette Dieterlen \\ Rio Tigris I37-9 \\ MEXICO 5 D.F.
}

\title{
MEXIQUE
}

Ma: chère Wièce,

J'éprouve le besoin de répondre immédiatement à votre lettre reçue ce matin. Je ne vous cache pas qu'elle me cause un certain embarras. Mes rapports avec Jacques Maritain ont toujours été un peu difficiles et ces dernières années, ils sont tombés à zéro. Je suis convaincu que vous avez ráison, et que son action en Amérique a pu être bénéfique. Mais je ne puis m'eppecher de trouver qu'il a adhéré beaucoup trop systématiquement au thomisme et est resté en somme beaucoup trop étranger au courant de la pensée moderne, et il m'a toujours semblé qu'il cherchait à compenser cet attachement à une pensée médiérale par un goût excessif da/l'avant garde, sur le plan artistique. Ceci, je vous 1'écris, pour vous expliquer mon attitude, mais je ne veuxà aucun prix que ce soit publié. Car je détesterais lui faire de la peine. C'est un très vieil homme qui doit être ménagé. Seulement, dans ces conditions, je préfère m'abstenir de collaborer au numéro en question.

Ne m'en veuillez pas, et croyez à 1'expression de ma très vive sympathie à laquelle ma belle soeur joint ses meilleurs compliments.

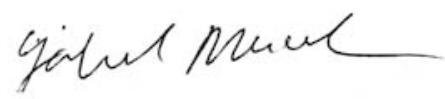

Diánoia, vol. LII, no. 59 (noviembre 2007). 
Mr. Gabriel MARCEL

21, rue de Tournon

PARIS VIème
París, 31 de enero de 1972

Mademoiselle Paulette Dieterlen

Río Tigris 137-9

MEXIQUE, 5, D.F.

Mi querida sobrina,

Siento la necesidad de responder inmediatamente a su carta, recibida esta mañana. No le oculto que me causó cierta incomodidad. Mis relaciones con Jacques Maritain siempre han sido un tanto difíciles y, en estos últimos años, se han reducido a cero. Estoy convencido de que tiene usted razón, y de que su actuación en América pudo haber sido benéfica. Pero no puedo evitar pensar que se afilió demasiado sistemáticamente al tomismo y permaneció, a final de cuentas, demasiado ajeno a la corriente del pensamiento moderno. Asimismo, siempre me ha parecido que buscaba compensar ese apego a un pensamiento medieval con un gusto excesivo por la vanguardia en el plano artístico. Esto se lo escribo para explicar mi actitud, pero por nada del mundo quiero que se publique. Pues no me gustaría hacerlo sentir mal. Es un hombre de edad muy avanzada que merece ser tratado con indulgencia. Lo único es que, en tales circunstancias, prefiero abstenerme de colaborar en el número en cuestión.

No me guarde resentimiento, y crea usted en la expresión de mi más viva simpatía, a la cual mi cuñada une sus mejores cumplidos.

Gabriel Marcel

[Traducción: Maurizio Tazzer Dieterlen] 